\title{
Racionalidade e representação: requisitos para a exploração dos limites do político
}

Reginaldo Teixeira Pérez ${ }^{1}$

\section{Introdução}

O objetivo deste trabalho será o exame dos conceitos de racionalidade e representação na constituição da ordem sócio-política. Mais especificamente, pretendese identificar o conteúdo desses conceitos em alguns autores representativos do pensamento político moderno e contemporâneo. Especial ênfase recairá sobre o universo liberal. O ordenamento dos argumentos: apresentar-se-ão definições provisórias de racionalidade e representação; logo a seguir, propor-se-á um interrelacionamento possível dos dois conceitos. Finalmente, a partir dessa associação, serão examinadas várias formas de relacionamentos entre representação e racionalidade e vice-versa - com ênfase na explicitação de suas resultantes sobre a ordem.

Embora o eixo analítico adotado neste trabalho tenha privilegiado a representação dentro da epistemologia liberal (e sua conseqüente justificativa racional) [item 1], bem como sua crítica [itens 2 e 3], não se limite à relação liberalismo/racionalida-

${ }^{1}$ Professor do Departamento de Sociologia e Política da Ufsm. Doutor em Ciência Política pelo Iuperj. 
de/representação x elitismo/irracionalidade/não-representação o estoque de conteúdos políticos possíveis nela envolvidos. As referências a Mancur Olson Jr. e Carl Schmitt, por exemplo, para além das próprias dificuldades referentes a Hobbes, sugerirão a inesgotabilidade do tema representação/racionalidade.

Apresentam-se as primeiras definições. (1) Evitando-se a polêmica sobre a universalidade ou não do conceito de racionalidade, cuja extensão vai da epistemologia à antropologia, define-se racionalidade aqui em um sentido próximo ao que Weber chamou de "ação racional instrumental" (zweckrational), ou seja, como o agir que busca fins ou objetivos específicos, procurando obtê-los com o emprego do cálculo e da adequação dos meios a esses fins (Weber 1987). Desse modo, os meios justificar-se-iam enquanto os mais eficazes para a obtenção de determinados fins. Limite-se este conceito a uma circunscrição antes cronológica do que lógica; Weber associou a razão instrumental com o capitalismo e o desenvolvimento da técnica e da sociedade industrial. (2) Ao reconhecer a impossibilidade prática de que o conjunto de cidadãos decida as questões relativas à agenda pública, impõe-se um mecanismo de engenharia política para tornar viável a tomada de decisões em uma sociedade complexa e diversificada. $\mathrm{O}$ instituto da representação requer a crença de que é possível A representar B (sendo B um indivíduo, um grupo ou um partido político) no parlamento, e que esta relação assuma na sua totalidade a dimensão fiduciária. $^{2}$

O enredo a ser seguido neste ensaio terá como questão central a possibilidade de a representação ser tomada como a forma mais racional -segundo as definições apresentadas e suas críticas- para a produção do ordenamento social, ou seja, à estabilidade institucional. A hipótese que se apresenta aponta cuidadosamente para a afirmação da indagação na maioria dos autores a serem examinados, tendose em conta duas condições: (1) privilegiar a dimensão normativa da representação, o que problematiza sua associação com racionalidade; (2) relativizar a extensão do conceito de racionalidade, limitando-o ao empregado no universo econômico. A partir dessa delimitação, tanto de racionalidade quanto de representação, pode-se pensar em uma intersecção que indique a representação como o meio mais adequado à obtenção da ordem.

${ }^{2}$ A obra $O$ governo representativo, de John Stuart Mill, é a que melhor traduz a positividade conferida pelo liberalismo à idéia de representação. 


\section{A representação desejável e possível (Mill e Dahl)}

Ao opor liberdade a autoridade, John Stuart Mill opera a cisão entre indivíduo e poder. Deste segundo divórcio resulta o limite entre dois mundos: o social e o político. Sendo a ordem desejável com o relacionamento desses dois universos, impõe-se a necessidade da construção de um mecanismo institucional que ligue esses dois mundos. A representação será o instituto responsável pela neutralização da tensão latente entre o desejo da decisão individual (liberdade) e a necessidade da decisão coletiva (obrigação política) para fins de estabilidade da vida social. Distintamente de seu interlocutor francês no continente -Alexis de Tocqueville, que enxergava uma oposição intransponível entre liberdade e igualdade-, o intelecto de Mill buscou a conciliação entre ambas na substantivação da liberdade e na formalização da igualdade.

Entenda-se como liberdade substantiva o espaço inviolável que possui -ou deve possuir- o indivíduo singular na sua relação com a instância reguladora por excelência da vida social a partir da modernidade, ou seja, o Estado. Como decorrência lógica, afirma-se a necessidade de se antepor limites a esse, seja qual for a sua natureza. Não se veja a necessidade de um Estado limitado apenas pela colocação do prius liberdade individual, mas sobretudo pelo questionamento de Mill à possibilidade de uma razão superior, dotada de excelência cognitiva, vir a ser portadora da verdade. Coerente com a tradição liberal de corte lockeano, Mill relativiza o saber não só pela constatação dos limites da razão, mas também pela falibilidade das instituições - que são obras humanas. Não está excluída a possibilidade do exercício da razão, cuja condição é a liberdade, mas problematizou-se seu alcance. Daí a importância da interação entre múltiplas razões.

Sendo um individualista metodológico, Mill encara o tecido social como um universo impregnado de diversidade em função das próprias diferenças individuais. Só um mecanismo exógeno à individualidade, sem negá-la, poderia transformar a diferença em semelhança. Apresenta-se aí a fonte das reservas com que Mill via o igualitarismo crescente das democracias européias, notadamente o resultante da Revolução Francesa. Trata-se, assim, de construir uma engenharia institucional que não destrua a diversidade social, afirmadora da liberdade individual. Há que se fabricar uma instituição ordenadora (o que virá a ser o governo representativo) que expresse e contenha a diversidade social. A diferença deverá instituir e constituir o órgão ordenador de modo a espelhar a sociedade. Estes são os pressupostos de Mill, o principal formulador de uma teoria normativa da representação. ${ }^{3}$

${ }^{3}$ Essas formulações encontram-se em Mill (1991). Para uma sucinta exposição do seu pensamento, ver Lafer (1991: 61-78) e Bobbio (1987: 107-28). Para uma apresentação da teoria da representação em Mill, ver Pitkin (1967: 177-97). 
Se em On Liberty havia um forte protesto à tirania de opinião, Considerations on Representative Government será uma receita contra a tirania da maioria. Neste último, haverá uma defesa intransigente da representação proporcional como sistema eleitoral. Objetiva Mill, com isso, garantir respeito pela diversidade ideológica. Essa fórmula institucional será o equivalente mais próximo do ideal do autogoverno. Em Mill, além de uma ética utilitária, pode-se afirmar que há também uma ética da representação.

Há uma aposta de Mill nos indivíduos singulares a partir de algumas condições básicas: a) eles "só estarão garantidos (...) na proporção em que têm o poder de se protegerem a si mesmos"; e b) "somente conseguem grau elevado de sucesso na luta contra a natureza na proporção em que são autodependentes, confiando no que eles mesmos são capazes de fazer, ou separadamente ou em conjunto, ao invés de confiarem no que terceiros venham a fazer por eles" (Mill 1983). Com isso, confirma-se a individualidade de Mill a partir de seres minimamente racionais, ativos e responsáveis que deverão garantir a existência de uma sociedade plural e tolerante. A condição imposta pelo autor à consecução de um governo representativo é a existência de um quadro de valores fortemente introjetado no tecido social que satisfaça as seguintes condições: a) "que o povo esteja disposto a recebê-lo" (o governo representativo); b) "que esteja disposto e seja capaz de fazer o que for necessário para preservá-lo"; e c) "que esteja disposto e seja capaz de cumprir com os deveres e desempenhar as funções que lhe impõe" (Mill 1983). A decorrência de tal formulação é que vontade e racionalidade individuais serão condições necessárias ao governo representativo.

O melhor governo, para Mill, é aquele no qual a soberania se encontra na comunidade. Sendo esta povoada por indivíduos que apresentam diferenças de todo tipo (sexo, raça, religião etc.), e, ao mesmo tempo, não havendo critérios objetivos de aferição de superioridade de uns sobre outros, todos devem ser representados no órgão ordenador. O parlamento deve ser o espelho da sociedade na sua diversidade e complexidade. $\mathrm{O}$ instituto da representação é anterior ao da decisão. O primeiro obedece ao princípio da não-exclusão (todos devem ser representados); o segundo, ao da lógica política. Estando todos representados, pode e deve valer o princípio da maioria - desde que a minoria não seja esmagada.

Segundo Mill,

"em qualquer democracia realmente igual, toda ou qualquer seção deve ser representada, não desproporcionalmente, mas proporcionalmente. Maioria de eleitores terá sempre maioria de representantes, mas a minoria dos eleitores deverá ter sempre uma minoria de representantes. Homem por homem, deverá ser 
representada tão completamente como a maioria. A menos que tal se dê, não há governo igual, mas governo de desigualdade e de privilégio: uma parte do povo manda na outra; retirar-se-á de certa porção da sociedade a parte justa e igual de influência na representação, contrariamente a todo governo justo, mas acima de tudo, contrariamente ao princípio da democracia, que reconhece a igualdade como o próprio fundamento e raiz" (Mill 1983: 89).

Desse modo, a substituição da democracia direta pela democracia indireta é operada sem qualquer perda de substância política. $\mathrm{O}$ indivíduo está representado na esfera pública por um igual, o que implica no reconhecimento de uma automática transferência da racionalidade individual à racionalidade coletiva. Inferencialmente, pode-se dizer que a ordem sócio-política -ou sua expectativa-, para Mill, já pode ser identificada no plano individual. Se esta ratio é condição necessária, mas não suficiente -como em Locke-, à produção da estabilidade, a interação de múltiplas razões segregará racionalidade. $\mathrm{O}$ espaço privilegiado para isso é o parlamento, órgão originador, disciplinador e controlador do governo - executor da policy.

Produzindo sua obra um século após Mill, Robert Dahl teve como objeto não uma sociedade de massas em formação, mas já plenamente estabelecida. Os Estados Unidos da América são o seu modelo, de onde advirão seus conceitos fundamentais. Em certo sentido, a obra de Dahl pode ser tomada como uma crítica à teoria das elites. Uma crítica pluralista que negará, em última análise, a possibilidade de existência de somente uma elite monolítica, propondo a tese da existência de várias elites. Definir-se-ia o sistema democrático exatamente como aquele em que as elites competem pela preferência do eleitorado. Argumento semelhante ao de Dahl será feito por Raymond Aron, estabelecendo as bases de uma crítica liberal à teoria das elites: "A diferença fundamental entre uma sociedade de tipo soviético e uma de tipo ocidental é que a primeira tem uma elite unificada enquanto que a última tem uma elite dividida" (Aron apud Bobbio 1986: 389).

Embora haja diferenças entre os modelos analíticos de Dahl e de Mill, as semelhanças não são nada desprezíveis: 1) a necessidade de um quadro de valores que preserve o mínimo; 2) este mínimo encerra a família das liberdades, à qual seguir-seão os mecanismos de igualdade formal; e 3 ) a necessidade de tolerância e o respeito às regras. $\mathrm{O}$ elemento sintetizador dessas três condições para a efetivação dos regimes pluralistas em Dahl é o consenso - quanto a meios. ${ }^{4}$ Quando Dahl se refere

${ }^{4} \mathrm{O}$ emprego por Dahl, assim como por Mill, da unidade analítica consenso causa estranheza. Mesmo que seja referido apenas quanto a meios, subverte a tradição liberal na sua afirmação da diversidade social que, no limite, reconhece em cada indivíduo uma unidade integralizada. Talvez 
à democracia, ficam subentendidos (a) a importância da liber na pólis e (b) o controle dos cidadãos sobre seus líderes, respectivamente, os elementos prescritivos e concretos da policy.

Em essência, a preocupação de Dahl em substantivar a liberdade e formalizar a igualdade é mais consequiente do que a de Mill quanto aos resultados de ambos os modelos, isto é, quanto à dimensão política das proposições. Dahl parece ter mais presente do que Mill as dificuldades da transformação da democracia política/ igualdade formal em democracia social/igualdade substantiva. Mais: seu modelo, que aproxima política e mercado, sugere exatamente a impossibilidade, ou indesejabilidade, dessa transformação. Isso não impede que a representação seja assumida por Dahl, à semelhança do que ocorre com Mill, como o ideal mais próximo do autogoverno.

O desdobramento da primeira e mais importante semelhança entre Dahl e Mill, qual seja, a necessidade de uma cultura propícia à confirmação de uma ordem democrática, aponta ao processo de socialização. A existência de uma rede de hábitos e atitudes inculcados na sociedade consubstanciam os controles internos, elementos centrais, mais do que os dispositivos institucionais, à estabilidade sócio-política. Os mecanismos institucionais -a representação, por exemplo- são vicários de um a priori: o apoio da população. Essa base cultural, segundo Dahl, confirmará -ou deverá confirmar- as oito condições axiomáticas à existência de uma poliarquia, a saber: liberdade de associação, expressão e voto; elegibilidade para o serviço público; direito dos líderes políticos a competir em busca de apoio e lutar por votos; diversidade de fontes de informação; eleições livres e imparciais, instituições que garantam que a política do governo dependa dos votos e demais formas de expressar as preferências.

Em essência, essas oito condições propostas por Dahl à consecução de um regime poliárquico resumem-se aos dois grandes pilares do projeto liberal-democrático, ou seja, a liberdade a e os direitos de. A família das liberdades circunscreve o que o autor chama de debate público; o quadro dos direitos é delimitado pela

fosse mais coerente, considerada a dissensualidade intrínseca da sociedade, falar em acordo de maioria quanto a meios, respeitados os direitos das minorias. Não se subestime a complexidade da questão, pois falar de meios é também falar de fins. Veja-se que a minoria pode considerar a violência um meio legítimo à luta política. Então, como proceder? Para uma discussão dessa questão, ver Bobbio (1987: 41-64). 
capacidade de representação. Há poliarquia quando essas duas variáveis (independentes) se aproximam do limite máximo, quer dizer, quando compatibiliza-se a maior liberdade possível com os direitos (formais) do maior número.

Ao qualificar as democracias modernas antes como governo de minorias do que governo de maiorias, Dahl caracteriza a poliarquia: é um sistema no qual todos os grupos ativos e legítimos da população podem se fazer ouvir em algum estágio crucial do processo de tomada de decisões (Dahl 1989b). Veja-se que, diferentemente de Mill -para o qual a unidade analítica básica era o indivíduo-, Dahl identifica no grupo a origem do mundo político. Claro está que há uma adesão anterior do indivíduo a esses grupos, mas o porquê desta adesão não parece ultrapassar os limites do interesse. Em Mill, os indivíduos eram representados; em Dahl, são os grupos representados. Para Dahl, portanto, o interesse é o cimento da sociedade. Ele é o elemento conferidor de racionalidade ao social que é transposto à esfera da politice automaticamente.

Em síntese, a racionalidade (subjacente) individual em Dahl -mínima, como em Mill- que motiva indivíduos a aderir a grupos, tem a mesma função ao nível do grupo que, orientado pelo interesse, busca a representação na pólis. A conseqüência da racionalidade do grupo em Dahl é, desse modo, a mesma da racionalidade individual de Mill: a conformação da ordem social. O meio que torna exeqüível esta operação é a representação.

\section{Hiper-racionalidade individual e estatal e representação desejável (Olson e Hobbes)}

As teorias liberal e pluralista, até agora sucintamente apresentadas, guardam em comum o que se chamou neste trabalho de racionalidade mínima dos indivíduos (Mill) ou de grupos (Dahl). Essa racionalidade é condição necessária e torna-se suficiente à efetivação da ordem sócio-política, segundo os autores examinados, com o auxílio da representação. A racionalidade que circunscreve o corpo político não é significativamente distinta e/ou diferente da que apresenta o corpo social, seja este composto por indivíduos ou grupos. É por isso que A pode representar B, dentro da canônica liberal, sem perda de substância política do representado.

Dentro do quadro de problematizações possíveis ao conceito de representação até agora desenvolvido neste ensaio, duas devem ser destacadas: a primeira é a que redefine, para maior, a extensão da racionalidade na esfera individual; a segunda, ao contrário, subestima o papel dessa mesma racionalidade. A primeira está 
presente na teoria sobre grupos de Mancur Olson Jr (Olson Jr. 1968); a segunda encerra o corolário de pressupostos dos teóricos elitistas, cujo exemplar mais significativo é Joseph Schumpeter (Schumpeter 1961). Ambas formulações, ao (re)delimitarem racionalidade, questionam a exeqüibilidade da representação, segundo princípios liberais e pluralistas, enquanto corpus intermediário eficiente à produção de estabilidade social.

Resumidamente, a tese olsoniana -publicada em meados da década de 60 deste século- questiona o interesse comum como elemento de suficiência à ação coletiva. Na ausência de incentivos seletivos ou coerção, grupos pequenos teriam maiores possibilidades de se organizar comparativamente aos grandes grupos. A decorrência é que a produção de bens coletivos (ou públicos) ficaria prejudicada em função do cálculo custo/benefício operada pelos indivíduos (ou pequenos grupos) em favor da não-cooperação, pois os benefícios seriam auferidos igualmente. O pressuposto do modelo de Olson é a existência de uma hiper-racionalidade na base da sociedade (individual ou grupal), que exclui qualquer possibilidade de solidariedade. A lógica da ação coletiva -que seria melhor definida se fosse apresentada em termos de a lógica da ação individual no coletivo- acaba pautada pela presença do carona (free-rider). No limite, haveria a impossibilidade de vida socialmente organizada sem a presença de um órgão suficientemente racional para exercer a coerção.

Desnecessária a demonstração do impacto causado por essa tese na epistemologia liberal, que defendia a sincronia da racionalidade do mundo social e do mundo político. A presença do sujeito que calcula e percebe que, não cooperando, ganha, desqualificou e exilou o projeto liberal que se sustentava exatamente na hipótese contrária. Com esta base, o ideário olsoniano problematiza substantivamente qualquer relação de cooperação voluntária entre indivíduos. A decorrência é que a relação entre representante e representado, independentemente da existência de interesses comuns, é impossível - a não ser como artifício.

Observada à luz do instrumental analítico dos séculos XIX e XX, a representação ainda apresenta dificuldades em relação ao conteúdo do conceito. Para um melhor enquadramento desse quadro, buscar-se-á nos primórdios da modernidade, especificamente na teoria política de Thomas Hobbes, a origem do conceito moderno de representação. ${ }^{5}$ Antes, reconheça-se já no medievo (desde o século XIII) a

5 Thomas Hobbes de Malmesbury, Leviatã ou: Matéria, forma e poder de um Estado eclesiástico e civil. Para uma sucinta apresentação da teoria da representação em Hobbes, ver Manent (1990: 37-62). 
luta da figura real -contra as forças descentralizadoras, privatistas e localistas-por uma maior concentração de poder, com a justificativa de que ela representava o projeto de unidade nacional.

Um dos motivos pelos quais Hobbes é considerado um dos fundadores do pensar político moderno deve-se ao seu rompimento com a tradição organicista de refletir a sociedade. Desde Aristóteles até os seiscentos prevaleceu uma concepção de indivíduo integrado naturalmente à vida social. ${ }^{6}$ Este indivíduo não detinha completude como ontos, a não ser em uma dimensão relacional. Em Hobbes, operase a subversão do modelo aristotélico em favor de uma visão individualista de sociedade (Bobbio 1990). Adquirindo integralidade ontológica, o indivíduo hobbeseano sofre de um duplo isolamento: analítico e social. Concorrem ambos para a percepção do social como uma construção humana. O homem hobbeseano é obrigado, portanto, a produzir o social.

Homo homini lupus. A definição de natureza humana em Hobbes, impregnada de negatividade, estabelece os parâmetros da sociabilidade (im)possível. Seres possessivos, egoístas e potencialmente destrutivos povoam um mundo de recursos escassos. O natural condition of mankind é um Estado caracterizado pela liberdade, mas a incerteza, a atomização e o medo tornam a vida miserável e curta especialmente curta. $\mathrm{O}$ temor de uma morte violenta e dolorosa conduz esses seres solitários a consultar a lei natural (razão) e, abdicando grande parcela da liberdade, estabelecem um pacto -cujo pressuposto é a obediência recíproca- em favor de um animal artificial. Troca-se, desse modo, a liberdade natural pela segurança. $\mathrm{O}$ responsável pela vida de todos concentrará poder suficiente para a manutenção do pacto. A salus populi será o objetivo daquele que foi criado com e como arte: o Estado, Leviatã ou Deus Mortal. Todos estão submetidos ao contrato fundador, menos ele, a besta-fera, que tem poder de vida e de morte.

A racionalidade individual, que é condição necessária à formulação mas não manutenção do pacto hobbeseano, acaba concentrada no sujeito de cognição

6 A posição de Aristóteles encontra-se no Capítulo 1 do Livro Primeiro de sua obra $A$ Política: "A partir dessas considerações, torna-se evidente que a cidade pertence àquela classe de coisas que existe por natureza, e que o homem é por natureza um animal determinado à vida social. (...) Podemos agora afirmar que (embora o indivíduo e a família sejam precedentes em termos temporais) a cidade é anterior na ordem da natureza em relação à família e ao indivíduo. A razão para isto é que o todo é necessariamente anterior (na natureza) à parte". A citação, traduzida para o português pelo autor deste ensaio, é extraída de Barker (1958: 5-6). 
superior, o Estado. ${ }^{7}$ Ao pactum unionis segue-se, necessariamente, um pactum subjectiones, elemento produtor da soberania. O pacto entre indivíduos singulares, que produz a transferência de seus direitos naturais -especialmente a liberdade- ao soberano, significa o reconhecimento de que as ações praticadas por este soberano são dos próprios indivíduos pactuantes, sejam elas quais forem. Ele é seu representante. A unidade do corpo político consiste nisso: todos os membros do corpo têm um mesmo representante, o soberano. ${ }^{8}$

Credita-se a Hobbes, assim, não só o primeiro dos direitos naturais, a vida, mas também outra categoria fundamental do projeto liberal - a representação. Bem entendido, ela materializa a relação simbólica do súdito com o monarca. O indivíduo autônomo do estado de natureza, ao pactuar com outros indivíduos autônomos, acorda em transferir poder privado ao soberano e se transforma em uma figura semi-heterônoma. Está fundado o poder de ou sobre todos, o poder público. Este mecanismo de transferência de poder recebe o nome de autorização. Ou seja: o poder público está autorizado a agir em nome dos pactuantes. A leitura política de Hobbes não pode deixar de assinalar o aparente paradoxo, origem do dilema da própria representação: o absolutismo de Hobbes é vicário de seu próprio individualismo, tanto quanto apesar dele. ${ }^{9}$

${ }^{7}$ No original, a sentença que sintetiza a idéia é: Covenants, without the sword, are but words e encontra-se no capítulo XVII de Leviathan.

${ }^{8}$ Para uma exposição da moderna teoria da representação em Hobbes, ver Tavares (1994, esp. 70ss). Neste trabalho, Tavares defenderá o que se qualificou de teoria prescritiva da representação, retomando os teóricos liberais -e também conservadores- defensores da representação, com especial destaque para Hobbes e Mill.

${ }^{9}$ Esta interpretação de Hobbes pode ser encontrada em Manent (1990, esp. cap. 3). Para uma crítica do conceito de representação em Hobbes, ver Pitkin (1967). Na página 11 da introdução, por exemplo, antecipa-se a essência da crítica que será desenvolvida no capítulo 1, "The problem of Thomas Hobbes": "Hobbes' definition is essentially formalistic, conceiving of representation in terms of formal arrangements which precede and initiate it: authorization, the giving of authority to act". Tavares concordará com as críticas de Pitkin: "A teoria hobbeseana da autorização é moderna e atual precisamente porque discerne o caráter público e publicizante da representação política, mas anula inteiramente as exigências de representação que partem dos segmentos particulares da sociedade sob a forma de conflito entre clamores privados concorrentes. Portanto, embora não seja falsa, a teoria hobbeseana é certamente -como observou Hanna Pitkin-, incompleta e unilateral" (op. cit.: 11). O cuidado lingüístico de Tavares oculta a expressão síntese de sua passagem: a teoria da representação em Hobbes não contempla os interesses. Daí sua longa argumentação de Hobbes a Mill. Posição crítica em relação a uma leitura liberal de Hobbes encontra-se em Bobbio (1991). 
O dilema da definição do conteúdo da representação deve ser associado ao dilema da definição do conteúdo da política liberal. A concepção hobbeseana não parece esgotar o conteúdo do conceito de representação. Se, por um lado, o mandato imperativo -ou, por delegação-, dos representantes dos estamentos medievais é superado com a visão hobbeseana, permanece o problema da dimensão semântica do conceito. Representar significa também, por exemplo, figurar dramática ou artisticamente, o que não implica antinomia à idéia hobbeseana de mandato virtual, mas sugere delicada diferença que possui conteúdo político substantivo. $\mathrm{O}$ indivíduo de Hobbes que pactua, trocando liberdade por segurança, mantém apenas o direito à vida. A questão é saber se apenas a vida é condição suficiente à sua transformação em cidadão. Em outros termos, pergunta-se: quem controla o sujeito de cognição superior?

Apresenta-se aqui outra dimensão funcional do conceito de representação, também pertencente à tradição liberal: o controle do poder. A esta tarefa dedicouse o não menos importante pensador inglês, também setecentista, John Locke, que fracionou o soberano, não o tornou imune aos interesses e, por fim, instalou-o no parlamento. Menos de um século depois, na esteira da revolução americana, a engenharia institucional construída pelos founding fathers reviveria o rei controlado (presidente), sem a negação da máxima "taxation without representation is tiranny".

A tradição liberal carrega consigo, bem como seu filho pródigo -o conceito de representação-, uma tensão de conteúdo político não desprezível: a liber possui uma íntima relação com a servidão. Seja pela submissão voluntária a um soberano; seja pela submissão a muitos soberanos. Defesa apaixonada da necessidade de autonomia do representante em relação ao representado, o que implica em confiança, é feita por Edmund Burke em Speech to the electors of Bristol. Produzida em 1774, esta obra descreve o papel do representante como um trabalho de razão e de juízo a serviço do bem comum e não do simples querer e dos preconceitos locais.

Entre a hiper-racionalidade do indivíduo olsoniano e a hiper-racionalidade do Estado hobbeseano coloca-se a posição intermediária do liberalismo moderno milliano. Este é quem (re)proporá a adesão à representação, mesmo que no interior de uma moldura prescritiva. É neste quadro que se supera, ou se tenta superar, a tensão da relação representante/representado como a forma mais racional de afirmação da ordem. 


\section{Irracionalidade, a impossibilidade da representação e a democracia como mercado (Rousseau e os elitistas)}

Mill conciliou os conceitos de estado parlamentar e democracia representativa. De um instituto historicamente prévio (estado parlamentar, pré-democrático), passa-se, com a participação política ampliada no século XIX, à democracia representativa, modelo último de formalização da igualdade. $\mathrm{O}$ voto irá igualar a participação. O modelo de racionalidade está conciliado com a idéia de representação. Poder e sociedade estão ao mesmo tempo conciliados e divorciados. O primeiro se origina na segunda, mas, ao mesmo tempo, está dela separado. Pois esta última dimensão da democracia representativa, ou seja, o hiato entre os que governam e os governados que, reconheça-se, não foi um problema para Mill, será a questão dos pensadores situados no final do século XIX e início do XX, reconhecidos como elitistas. ${ }^{10}$

Ao contrário da dimensão prescritiva da teoria política de Mill, os elitistas -ou realistas- terão como principal objetivo a descrição da realidade. E esta é bastante clara: em toda sociedade, independentemente de tempo e lugar, existiu sempre uma minoria que foi detentora do poder, em detrimento de uma maioria que dele foi privada. Da metodologia descritiva à lógica dualista necessária poder/minoria dominados/maioria, obedece-se a preceitos que remontam ao quinhentista Maquiavel: "Porque o objetivo do povo é mais honesto do que o dos poderosos; estes querem oprimir e aquele não ser oprimido" (Maquiavel 1983: 40). Ironicamente, a passagem do aqui normativo Maquiavel denota, com sinal invertido, aquela que seria a principal preocupação dos elitistas, isto é, as conseqüências políticas da emergência das massas na cena pública. Mais precisamente, a sobrevivência da democracia estaria intimamente ligada à capacidade de as elites protegerem o sistema contra a irracionalidade da massa. ${ }^{11}$

\footnotetext{
${ }^{10}$ Para uma apresentação das teses elitistas, ver Bobbio (1986: 385-91); ver também Bachrach (1967)

${ }^{11}$ Não se limite aos elitistas a visão da massa encapsulada pela irracionalidade. Veja-se a seguinte passagem do liberal von Mises, criticando o próprio liberalismo, em publicação da década de 1920: "Os liberais manifestavam a opinião de que todos os homens tinham a capacidade intelectual para raciocinar corretamente acerca dos difíceis problemas da cooperação social, e, por isso, de agir em conformidade. Estavam tão impressionados com a clareza e evidência do raciocínio, pelo qual haviam chegado às suas idéias políticas, que se mostravam incapazes de compreender como alguém poderia deixar de apreendê-lo. Nunca perceberam dois fatos: em primeiro lugar, que as massas carecem da capacidade de raciocinar logicamente; e em segundo, que aos olhos da maioria das pessoas, mesmo quando são capazes de reconhecer a verdade, uma
} 
Grosso modo, esse foi o núcleo temático das obras de Gaetano Mosca, Vilfredo Pareto e Robert Michels. Adicional ou paralelamente, podem ser considerados também elitistas Max Weber e Vladimir Ilitch Ulianov (Lênin). Finalmente, Joseph Schumpeter - interseccionador da teoria elitista e do método econômico na política. Nesta parte do trabalho, far-se-á uma sucinta apresentação da teoria schumpeteriana -recuperando-se quando necessário os elitistas precedentes-, com o objetivo de examinar em que sentido há um rompimento ou concordância com os conceitos de representação e racionalidade até agora apresentados. Como resultado, emergirão as formas pelas quais se constitui, para os elitistas, o ordenamento social e político.

A publicação da obra Capitalismo, socialismo e democracia, do economista austríaco Schumpeter, no decorrer da segunda guerra mundial, pode ser considerada um marco da doxa negativa sobre o homem comum - tese prevalecente desde o final do século XIX. Nela, a questão democrática, definida aqui enquanto participação política ampliada, é discutida em novos termos. Não se limita a fazer uma crítica à teoria clássica da democracia, mas a redefine inteiramente. Lembre-se que Rousseau, primeiro grande pensador democrático moderno, havia formulado um conceito de democracia cuja base era a idéia da soberania do povo. O demos, isto é, o populus deveria governar - kratein. Em Rousseau, o elemento sedimentador da complexa relação entre corpo social e corpo político é a categoria vontade geral.

A dimensão revolucionária do pensamento do genebrino Rousseau não se limitava à subtração da soberania do corpo do rei ou do parlamento, mas calcavase sobretudo na negação da efetividade do corpo intermediário representação. Isto por um motivo: demanda a representação a idéia de transferência de vontade. Como vontade é intransferível, a representação como mecanismo de afirmação de soberania é impossível. Veja-se a seguinte passagem:

“A soberania não pode ser representada pela mesma razão por que não pode ser alienada, consiste essencialmente na vontade geral e a vontade absolutamente não se representa. É ela mesma ou é outra, não há meio-termo. Os deputados do povo não são nem podem ser seus representantes; não passam de comissários seus, nada

\footnotetext{
vantagem especial momentânea, de que possam gozar imediatamente, parece mais importante do que um ganho maior e duradouro, que tenha de ser postergado. A maioria das pessoas não possui nem mesmo os dotes intelectuais exigidos para analisar o problema (antes de mais nada, muito complicado) da cooperação social e, por certo, não dispõe da necessária força de vontade para fazer os sacrifícios provisórios que a ação social exige" (1987:155).
} 
podendo concluir definitivamente. É nula toda lei que o povo diretamente não ratificar; em absoluto, não é lei. O povo inglês pensa ser livre e muito se engana, pois só o é durante a eleição dos membros do parlamento; uma vez estes eleitos, ele é escravo, não é nada". ${ }^{12}$

Por outro lado, a ambigüidade rousseauniana se apresenta plenamente quando reivindica o posicionamento da soberania no povo e, ao mesmo tempo, reconhece que uma verdadeira democracia jamais existiu nem existirá. As dificuldades são de toda ordem, mas sobressaem-se o tamanho das sociedades modernas (século XVIII), a multiplicidade dos costumes e a desigualdade de condições e fortunas. A conclusão: "Se existisse um governo de deuses, governar-se-ia democraticamente. Mas um governo assim perfeito não é feito para os homens". ${ }^{13}$ A melhor organização política, para Rousseau, portanto, seria aquela em que os citoyens decidissem diretamente as questões públicas. Para tanto, as sociedades deveriam ser pequenas (máximo de 30.000 habitantes), ter uniformidade cultural e eqüidade material. Estão apresentadas as condições para a democracia direta.

A crítica schumpeteriana à teoria clássica da democracia, cujo representante nomeado aqui foi Rousseau, inicia-se pelo próprio conceito de democracia. Apresenta a moderna teoria da democracia a colocação da soberania no povo, derivando-se desta situação a legitimidade do corpo político. O objetivo último da ordem política, desse modo, seria a própria democracia enquanto governo do povo. Para Schumpeter, a democracia não pode ser um fim em si mesma; limita-se ela a um método político. Ou seja, é um certo tipo de ordenamento institucional para a tomada de decisões (Schumpeter 1961: 295ss). Em outros termos, a definição schumpeteriana de democracia é procedimental, isto é, encerra um conjunto de regras à produção do poder.

Schumpeter vai além de Rousseau quanto à impossibilidade prática da democracia direta. Questiona o próprio bem comum como fim último de indivíduos minimamente racionais (lembre-se do utilitarismo de Mill). Mais: duvida da própria existência dessa racionalidade mínima. Em última análise, problematiza definitivamente o conceito de vontade geral, elemento axial da teoria política rousseauniana. Com isso, rejeitaram-se os pressupostos do liberalismo, notadamente o da racionalidade individual. E, como conseqüência, a racionalidade coletiva e a representa-

${ }^{12}$ Rousseau (1978: 107-08). Para uma discussão sobre a impossibilidade da representação em Rousseau, ver Pitkin (1967: 51-72).

${ }^{13}$ Não se rejeite, em princípio, uma leitura que demonstre o elitismo de Rousseau. A figura do legislador, em substituição ao governo dos homens, parece sugerir essa interpretação. 
ção. Como explicar, então, a persistência do parlamento como segregador de racionalidade e, como decorrência, afirmador da ordem? A resposta de Schumpeter está na substituição da figura preposicional, isto é, a democracia deixa de ser o governo do povo e passa ser o governo para o povo - o que não exclui a idéia de governo aprovado pelo povo. Tradução: o parlamento deixa de ser um corpo intermediário e passa a ser um órgão de Estado. Reafirmou-se a relação governantes-governados sem intermediações.

A problematização sobre a exeqüibilidade da efetivação da vontade do povo em sociedades massificadas está vinculada às dificuldades no funcionamento da democracia. Sua administração demanda requisitos de qualidades e técnicas especiais. Ou seja, haverá a necessidade de confiar algumas das tarefas a especialistas. Neste ponto, a teoria schumpeteriana lembra Weber e reproduz quase fielmente a tese de Michels (Michels 1972). A questão apresentada indaga sobre as possibilidades de materialização da eqüidade na democracia. Em Weber, este problema se apresenta a partir da indispensabilidade da máquina política -leia-se burocracia-, com a conseqüente centralização das decisões, não obstante ele reconhecesse que a democracia deveria lutar contra a tendência à burocratização. ${ }^{14}$ Há em Weber um primeiro esboço do que seria plenamente desenvolvido por Michels.

O trabalho de Robert Michels, sugestivamente intitulado Os partidos políticos: um estudo sociológico das tendências oligárquicas da democracia moder$n a$, apresenta a seguinte hipótese: a democracia conduz à oligarquia; ela contém necessariamente um núcleo oligárquico. Desdobrando-se a afirmação, temos que os partidos políticos, fundamento da democracia representativa, são organizações que, na busca de uma maior racionalidade (leia-se eficácia na luta pelo poder), reivindicam trabalho especializado. Esta divisão do trabalho conduz à hierarquização no interior do partido, o que é o mesmo que sua oligarquização. Então a máxima de Michels: "quem diz organização, diz oligarquia". ${ }^{15}$ Rompe-se a cadeia que teria na base a igualdade substantiva e, através de mecanismos institucionais -no caso, os partidos políticos-, chegar-se-ia a uma outra igualdade não menos legítima, a igualdade formal.

${ }^{14}$ Gerth e Mills (s. d.: 31). Sobre o pensamento de Weber, ver também Aron Max Weber (Aron 1987: 461-40); Cohn Introdução a Weber (Cohn 1982: 7-36). De Weber, ver A política como vocação (Gerth e Mills s. d.)

${ }^{15}$ Michels (1972: v. 1, p. 13). Sobre o pensamento de Robert Michels, ver Lipset Introduccion à los partidos políticos.... In: Michels (1972: v. 1, p. 13-43); ver também Santos (1988: 11042). 
Está apresentada a lei de ferro da oligarquia, que demonstra, segundo Michels, a incompatibilidade entre a democracia e a organização social em grande escala. Se a democracia com base nos partidos políticos leva obrigatoriamente a uma elitização, a representação como instrumento legítimo de afirmação da participação política inexiste. Lembre-se que o objeto do estudo de Michels foi o Partido Socialista (social-democrata) alemão, isto é, situado à esquerda do espectro ideológico. Isso não evitou - ao contrário - a constatação:

"A acumulação do poder nas mãos de algumas pessoas relativamente pouco numerosas, tal como se dá no movimento operário, conduz fatalmente a inúmeros abusos. O 'representante', com a força de se saber indispensável, transforma-se facilmente de servidor em senhor do povo. Os chefes que no início eram mandatários de seus subordinados, acabam por ser os seus mandantes" (Michels 1972: v. 1, p. 188).

O esboço de uma crítica à tese de Michels pode ser encontrado ainda no interior do argumento elitista. O superdeterminismo da relação democracia-aristocracia, não obstante a aceitação por Michels da tese weberiana de que a mudança social é vicária da liderança carismática, foi arrefecido antes por Weber e após por Schumpeter pelo mecanismo da competição. Ambos insistiram que o elemento mais característico e mais valioso da democracia é a formação de uma elite política na luta competitiva pelos votos de um eleitorado fundamentalmente passivo. Dentro dessa lógica, a competição atenuaria a questão do poder, como se pudesse corroê-lo.

Tendo como principal alvo os pressupostos da liberal-democracia, especialmente sua vertente racional-utilitária de corte rousseauniano e milliano, Schumpeter -dando sequência a Pareto e Michels-identifica a prevalência do elemento extraracional ou irracional no comportamento social. O indivíduo singular, por desinformação ou distanciamento - o mais provável é a presença de ambos -, é interpelado pelo discurso político que, estrategicamente, o seduz pela emoção. ${ }^{16} \mathrm{O}$ drama existencial humano, de não poder escapar a uma racionalidade limitada ou a

${ }^{16}$ Clássica na Ciência Política, a fórmula: A tem poder sobre B quando consegue alterações no comportamento de $B$ conforme intenções previamente estabelecidas remonta - para ficarmos no mundo moderno- a Maquiavel: “...é preciso ser bom simulador e dissimulador (...) Todos vêem o que tu pareces, mas poucos o que és realmente" (1983: cap. 18). Leitores atentos de Maquiavel, os elitistas demonstraram em suas obras ter aprendido a lição de que o fazer política -em especial, na democracia- requer produção de emoção: "Não há multidão capaz de resistir ao poder estético e emocional da palavra (...). Nos estados democráticos impera a convicção de que somente o dom da palavra torna apto a dirigir os negócios públicos” (Michels 1972: v.1, cap. 5). 
uma irracionalidade consciente, foi assumido pelo liberalismo de cunho pragmático e/ou político. Isso não impediu que o liberalismo econômico -afirmador da sociedade de mercado- transformasse as paixões em interesses. Com isso, a satisfação pessoal vinculou-se ao mundo material. A dúvida, sem chegar aos limites do ceticismo absoluto, foi -e é- um poderoso instrumento de afirmação do processo cognitivo. Interseccionam-se aqui, isto é, nos limites do humano, o liberalismo ético e a política. A manipulação operada pela propaganda prejudica o discernimento, reafirmando-se a debilidade do elemento lógico dos que não têm envolvimento direto com a política - a esmagadora maioria. A produção da emoção, condição à ação coletiva, reivindica em seguida o seu contrário, a estabilidade, larva de um social sine ira et studium. Centrando na elite o elemento ativo da política, Schumpeter acaba por negar qualquer vontade do povo, substituindo-a pela vontade manufaturada (Schumpeter 1961: cap. 22).

Neutralizar a irracionalidade coletiva; este objetivo, que tanto preocupou Pareto, será função da liderança, na definição de Schumpeter. Inverte-se aqui a premissa liberal do eleitor racional que tem preferências, pela máxima elitista de que o líder disputa com outros líderes fatias do mercado político. Abandona-se a racionalidade mínima que detinha o indivíduo por uma racionalidade concentrada na liderança política, responsável pela ordenação do universo sócio-político. Da ação da liderança, que Weber chamou de políticos profissionais, dar-se-á a segregação de racionalidade. Esta, advinda do mundo político, chegará ao social. Dentro desse

No penúltimo capítulo de O Príncipe $\left(25^{\circ}\right)$ Maquiavel apresenta o dilema maior da condição humana - forjadora de emoção porque em boa medida são invisíveis os limites da razão com a paixão. Isso acaba por ter uma tradução dramática no mundo da política (luta pelo poder), ou seja, o paradoxo de saber da inexorabilidade do destino e, ao mesmo tempo, lutar contra ele. A busca do reconhecimento é a expressão desse drama. Não por acaso, Rousseau identificará nas paixões as motivações últimas das ações humanas; Hegel denominará de thymos esta busca desesperada que, em última instância, será a tentativa de superação da incomunicabilidade do ego com o alter - o que não exclui a busca de contato do ego consigo mesmo. Esse drama se apresenta em Weber na forma de uma contradição: "A política é feita com a cabeça, e não com outras partes do corpo ou da alma (...) A política é feita, sem dúvida, com a cabeça, mas certamente não é feita apenas com a cabeça" (Weber s. d. [A política como vocação]: 139, 151).

O drama existencial humano, de não poder escapar a uma racionalidade limitada ou a uma irracionalidade consciente, foi assumido pelo liberalismo de cunho pragmático e/ou político. Isso não impediu que o liberalismo econômico -afirmador da sociedade de mercado- transformasse as paixões em interesses. Com isso, a satisfação pessoal vinculou-se ao mundo material. A dúvida, sem chegar aos limites do ceticismo absoluto, foi -e é- um poderoso instrumento de afirmação do processo cognitivo. Interseccionam-se aqui, isto é, nos limites do humano, o liberalismo ético e a política. 
quadro, a função da luta política é conferir racionalidade à instabilidade da foule, que não passaria de um estouro de boiada. Mais especificamente, a democracia competitiva (leia-se eleitoral), na acepção schumpeteriana, teria a função de organizar a incerteza. A ordem possível, portanto, para Schumpeter, não está calcada na representação, mas sim no mercado.

Tendo Schumpeter rejeitado a tese liberal da existência de uma racionalidade individual mínima, defenestra ao mesmo tempo a idéia de representação - que só terá sentido como ficção. A unidade analítica que substituirá a representação no arcabouço teórico de Schumpeter será o mercado. Este, na clássica definição de Pareto,

caracteriza-se pela existência de indivíduos que possuem tanto necessidades quanto recursos em determinado tempo e lugar; são livres -os indivíduos- para produzir e trocar bens e serviços. Na situação ideal, isto é, quando há equilíbrio, as expectativas individuais se satisfazem e todos os mercados são claros. Nesse sistema, o sistema de preços tem o poder de informar os indivíduos não só sobre suas preferências e escassez relativa de diversos bens e serviços, mas também as oportunidades que deixam de ser aproveitadas. O resultado é que os recursos são alocados de tal modo que todos os ganhos do intercâmbio são exauridos; ninguém pode melhorar sua situação sem piorar a de outros; e a distribuição de bem-estar resultante não seria alterada na vigência de uma regra de unanimidade. Apresentaram-se os limites da ação social que segregam racionalidade coletiva. Situação também conhecida como ótimo de Pareto (apud Przeworski). ${ }^{17}$

Boa parte do esforço intelectual de Pareto foi transpor essa racionalidade do mundo econômico para a esfera social. A distinção das ações lógicas -associadas à racionalidade, à objetividade e à atividade econômica- das ações não lógicas vinculadas à irracionalidade, à subjetividade e ao mundo social- buscava uma compreensão que se propunha, em última análise, à conferência de harmonia em um mundo agônico resultante da massificação. Se Pareto tentou impregnar de racionalidade a sociedade a partir do método econômico, Schumpeter esforçar-se-á em submeter a democracia competitiva, sinônimo de política, ao mesmo regramento do mercado econômico. Para Schumpeter, portanto, a produção da ordem social é o elemento incidental da luta política, isto é, disputa por cargos e funções de mando, do mesmo modo que a produção é incidental à obtenção do lucro.

Embora questionem a efetividade da representação, elitistas como Mosca e Schumpeter tomam-na como algo importante na solução do problema da estabilida-

${ }^{17}$ Sobre o pensamento de Pareto, ver Aron Vilfredo Pareto (Aron1987: 377-460). Ver também Finer (1967: 3-88). 
de política. Não se subestima a centralidade da relação representaçãogovernabilidade, mas demonstra-se (especialmente com Schumpeter) uma outra dimensão da ideologia liberal, constante na democracia representativa: a transposição da virtualidade da representação para a virtualidade da política liberal. Quando da apresentação de Mill, referia-se a uma ética da representação; nos elitistas em geral e em Schumpeter em particular, pode-se falar em uma estética da representação. A imagem mais adequada para a proposição talvez seja a da história como teatro. A linguagem poética de Alfred de Grazia descreve o processo de representação: "uma ação teatral gerida por atores autônomos nos limites fixados pelo Estado, pelo ambiente e por mutáveis gostos dos espectadores. Estes atores desenvolvem um papel significativo, mas este papel não tem nenhuma relação direta com o bilhete de ingresso pelo qual os espectadores fazem fila" (apud Campilongo 1988:30).

Independentemente de se saber se é a representação a forma mais racional de afirmação da ordem, do que parecem duvidar os elitistas -não obstante a defendam-, a questão é se pode ela produzir uma ordem mais justa. Apresenta-se aqui o justo limitado à capacidade de o sistema representativo apresentar respostas aos apelos populares, substantivando a igualdade formal. Nesse sentido, sintetizador do justo é o conceito de responsividade de Hanna Pitkin. Quase vinte anos após a publicação do seu The Concept of Representation, escreveu no prefácio à edição espanhola que existe a probabilidade de as instituições representativas traírem, ao invés de servirem à democracia e à liberdade, e excluírem, ao invés de integrarem participativamente, a maioria da população do processo de decisão política (apud Campilongo 1988: 35).

Pois essa tensão apresentada pelos elitistas de, ao mesmo tempo, demonstrarem a dimensão falaciosa da democracia liberal e, por outro lado, reconhecerem sua inevitabilidade, não foi aceita com a mesma tranqüilidade por outros autores. Contemporâneo de Schumpeter, o jurista Carl Schmitt talvez seja o maior crítico da liberal-democracia. Esse autor alemão dirige sua verve notadamente à falta de transparência da luta política parlamentar (Schmitt 1985). A dimensão da crítica de Schmitt ao projeto liberal e, em especial, à idéia de representação pode ser tomada metaforicamente por uma cena do filme $O$ Piano. Nela, um Maori do século XIX, nativo neozeolandês, assiste a uma peça de teatro apresentada por colonizadores britânicos. Em um determinado momento, uma criança é ameaçada por um homem. Isso leva o nativo a, prontamente, invadir o palco e defender a criança. A ameaça do Maori à encenação expressa sua incompreensão, e/ou inaceitação, à concepção de representação reconhecida no ocidente. 
O grande projeto liberal, junto com suas instituições, traz consigo tanto a ambigüidade do conteúdo da política quanto o dilema do fazer política (lembre-se de Weber e Maquiavel). Isso constitui, ao mesmo tempo, a miséria e grandeza do liberalismo. Às vezes, a razão não o aceita - ou porque não o entende, ou, paradoxalmente, porque ele se esclarece.

\section{Notas Conclusivas}

Lembremo-nos da proposição inicial desse trabalho: a partir de definições de racionalidade e representação, operar-se-ia uma aproximação possível entre ambos e, a partir dela, analisar-se-ia o seu rendimento em autores escolhidos. Os conceitos escolhidos foram a racionalidade instrumental na concepção weberiana e a representação na dimensão liberal. A questão síntese retirada de ambos circunscreveu as possibilidades da formulação da ordem. Em outros termos, se pode a representação ser tomada como o mais racional instrumento à consecução da ordem sócio-política. Para além das limitações dos conceitos de racionalidade e representação apresentados como paradigmas, sugeriu-se que a política encerra dimensões mais amplas e complexas do que os conceitos oferecem, bem como sua inter-relação. Pode, e deve, ser tomada (a política) como a expressão de um ontos que procura antes respostas à sua própria condição. A busca da ordem sóciopolítica é uma transposição para o social do próprio dilema da ordem interior, fracionada e dilacerada. A referência a Maquiavel aponta a esta direção, ou seja, os pactos são efêmeros e instáveis. Dito de outra forma, a possibilidade de ordenação do mundo permanece circunscrita à sua expectativa.

A questão do trabalho pode ser recolocada nos seguintes termos - problematicamente axiomáticos: a) a essência da sociedade de mercado, reivindicadora de racionalidade coletiva, é a família das liberdades, na qual tem especial destaque o espaço ao acúmulo de bens ilimitadamente; b) a essência da democracia é a família dos direitos, dentre eles o da participação política ampliada, cuja base é a idéia da representação. A questão que emerge dos axiomas é sobre a compatibilidade entre ambos. Uma das hipóteses, mais sugerida do que desenvolvida neste ensaio, é que embora a democracia possa ser pensada como mercado -e isto certamente alivia tensões geradas pelos elementos não mensuráveis da política, como ideologia, por exemplo-, permanece o problema da "irredutibilidade". Mais precisamente, o método da economia, não obstante render muito analiticamente quando o objeto é democracia eleitoral competitiva, não dá conta de toda a dimensão da política, se é que há um método que o faça. 
Desdobrando-se o quadro hipotético defendido no trabalho, tem-se que a) a política não se reduz à representação; b) o indivíduo singular não se reduz à racionalidade. Deduz-se da vinculação dos axiomas a) e b) que 1) racionalidade e representação foram instrumentos necessários, mas não suficientes, à consecução do ordenamento social; 2) credite-se à concepção liberal a afirmação de que a representação é a forma mais racional à estabilidade. $\mathrm{O}$ manuseio nas entranhas da história não nos autoriza a absolutizar um saber para o presente $\mathrm{e}$ muito menos predizer o futuro. Há limites colocados à cognição plena que, mesmo quando observados a partir da insignificância temporal de nossa existência no mundo -a despeito de um patrimônio cultural conjunto-, parecem menores do que realmente são. A prudência sugere que, sendo a razão limitada, suas conseqüências também o são.

\section{Bibliografia}

Aron, Raymond (1987). As etapas do pensamento sociológico. $2^{\mathrm{a}} \mathrm{ed}$. Trad. Sérgio Bath. São Paulo: Martins Fontes; Brasília: UNB.

Bachrach, Peter (1967). Crítica de la teoría elitista de la democracia. Trad. Leandro Wolfson. Buenos Aires: Amorrortu Editores.

Barker, Ernest (1958). The politics of Aristotle. Trad. Ernest Barker. London: Oxford University Press.

Bobbio, Norberto (1986). Teoria das Elites (Verbete). In: Norberto Bobbio, Nicola Matteucci e Gianfranco Pasquino. Dicionário de política. Trad. Luís Guerreiro P. Cacais, João Ferreira, Gaetano Lo Mônaco, Renzo Dini e Carmen C. Varrialle. Brasília: UNB, p. 385-391.

(1987). O futuro da democracia: uma defesa das regras do jogo. Trad. Marco Aurélio Nogueira. Rio de Janeiro: Paz e Terra.

(1990). Liberalismo e democracia. Trad. Marco Aurélio Nogueira. $3^{\text {a }}$ ed. São Paulo: Brasiliense.

(1991). Thomas Hobbes. Trad. Carlos Nelson Coutinho. Rio de Janeiro: Ed. Campus.

(s. d.). Pareto e a crítica das ideologias. In: Norberto Bobbio. Ensaios esco-

lhidos - história do pensamento político. Trad. Sérgio Bath. São Paulo: C. H. Cardim, p. 127-155.

Boudon, Raymond e François Bourricaud (1993). Pareto (Verbete). In: R. Boudon e F. Bourricaud. Dicionário crítico de sociologia. Trad. Maria Letícia Guedes 
Alcoforado e Durval Ártico. São Paulo: Ática, p. 420-427.

(1993) Racionalidade (Verbete). In: R. Boudon e F. Bourricaud. Dicionário crítico de sociologia. Trad. Maria Letícia Guedes Alcoforado e Durval Ártico. São Paulo: Ática, p. 455-462.

Campilongo, Celso Fernandes (1988). Representação política. São Paulo: Ática.

Cohn, Gabriel (org.) (1982). Max Weber. $2^{\mathrm{a}}$ ed. São Paulo: Ática.

Cotta, Maurizio (1986). Representação política (Verbete). In: Norberto Bobbio, Nicola Matteucci e Gianfranco Pasquino. Dicionário de política. Trad. Luís Guerreiro P. Cacais, João Ferreira, Gaetano Lo Mônaco, Renzo Dini e Carmen C. Varrialle. Brasília: UNB, p. 1101-1107.

Dahl, Robert A. (1989a). La poliarquía - participación y oposición. Trad. Julia Moreno San Martin. Madrid: Editorial Technos.

_ (1989b). Um prefácio à teoria democrática. Trad. Ruy Jungmann. Rio de Janeiro: Jorge Zahar.

Finer, Samuel Eward (1967). Introduction. In: S. E. Finer (org.). Vilfredo Pareto sociological writings. Trad. Derick Mirfin. $3^{\mathrm{a}}$ ed. New York: Frederick A. Praeger Publishers, p. 3-91.

Gerth, H. H. e C. W. Mills (s. d.). Ensaios de Sociologia. $2^{\mathrm{a}}$ ed. Rio de Janeiro: Zahar. Gray, John (1988). O liberalismo. Trad. M. H. Costa Dias. Lisboa: Editorial Estampa. Lafer, Celso (1991). Ensaios liberais. São Paulo: Siciliano.

Locke, John (1978). The second treatise of government. New York: The Library of Liberal Arts, 1952.; Segundo Tratado sobre o Governo. In: Locke. Trad. Anoar Aiex e Jacy Monteiro. $2^{\mathrm{a}}$ ed. São Paulo: Abril Cultural (Coleção Os pensadores).

Macpherson, Crawford Brough (1978). A democracia liberal: origens e evolução. Trad. Nathanael C. Caixeiro. Rio de Janeiro: Zahar Editores.

Malmesbury, Thomas Hobbes de (1979). Leviatã ou Matéria, Forma e Poder de um Estado Eclesiástico e Civil. In: Hobbes. Trad. João Paulo Monteiro e Maria Beatriz Nizza da Silva. $2^{\mathrm{a}}$ ed. São Paulo: Abril Cultural (Coleção Os pensadores); Leviathan, or The matter, forme e power of a common-wealth ecclesiasticall and civill (1968). England: Penguin Books.

Manent, Pierre (1990). História intelectual do liberalismo - dez lições. Trad. Vera Ribeiro. Rio de Janeiro: Imago Editora.

Maquiavel, Nicolau (1983). O príncipe. In: Maquiavel. Trad. Lívio Xavier. $3^{\text {a }}$ ed. São Paulo: Abril Cultural (Coleção Os pensadores). 
Matteucci, Nicola (1986). Liberalismo (Verbete). In: Norberto Bobbio, Nicola Matteucci e Gianfranco Pasquino. Dicionário de política. Trad. Luís Guerreiro P. Cacais, João Ferreira, Gaetano Lo Mônaco, Renzo Dini e Carmen C. Varriale. Brasília: UNB, p. 686-705.

Merquior, José Guilherme (1991). O liberalismo antigo e moderno. Trad. Henrique de Araújo Mesquita. Rio de Janeiro: Nova Fronteira.

Michels, Robert (1972). Los partidos políticos: un estudio sociológico de las tendencias oligárquicas de la democracia moderna. 2 v. Trad. Enrique Molina de Vedia. Buenos Aires: Amorrortu Editores.

Mill, John Stuart (1983). O governo representativo. Trad. E. Jacy Monteiro. São Paulo: Ibrasa.

(1991). Sobre a liberdade. $2^{\mathrm{a}}$ ed. Trad. e Pref. Alberto da Rocha Barros. Petrópolis: Vozes.

Mises, Ludwig von (1987). Liberalismo: segundo a tradição clássica. Trad. Haydn Coutinho Pimenta. Rio de Janeiro: José Olympio/Instituto Liberal.

Olson Jr., Mancur (1968). The logic of collective action - public goods and the theory of groups. New York: Schocken Books.

Pitkin, Hanna Fenichel (1967). The concept of representation. Berkeley: University California Press.

Przeworski, Adam. The neoliberal fallacy. Journal of Democracy, 3(3): 45-50.

Rousseau, Jean Jacques (1978). Do contrato social. In: Rousseau. Trad. Lourdes Santos Machado. São Paulo: Abril (Coleção Os pensadores).

Santos, Wanderley Guilherme dos (1988). Paradoxos do liberalismo - teoria e história. São Paulo: Vértice; Rio de Janeiro: Iuperj.

Schmitt, Carl (1985). The crisis of parliamentary democracy. Trad. Ellen Kennedy. Boston: MIT.

(1992). O conceito do político. Trad. Álvaro L. M. Valls. Petrópolis: Vozes.

Schumpeter, Joseph Alois (1961). Capitalismo, socialismo e democracia. Trad. Japy Freire. Rio de Janeiro: Fundo de Cultura, Parte IV (Capítulos 20, 21, 22 e 23).

Tavares, José Antônio Giusti (1994). Os sistemas eleitorais nas democracias contemporâneas: teoria, instituições, estratégia. Rio de Janeiro: Releme-Dumará.

Weber, Max. (s. d.). Parlamentarismo e governo numa Alemanha reconstruída. In: Max Weber. Trad. M. Tragtemberg, São Paulo: Abril (Coleção Os pensadores). 
(1987). A ética protestante e o espírito do capitalismo. Trad. M. Irene de Q.

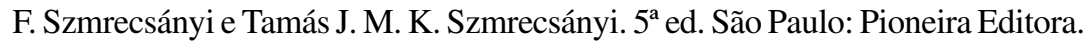
(s. d.). A Política como Vocação. In: Ensaios de Sociologia. Trad. Waltensir Dutra. $2^{\text {a }}$ ed. Rio de Janeiro: Zahar, p. 97-153. 